\title{
Justification of the optimal annual load on the tractor providing for its parameters stress on the formed crop
}

\author{
Camill A. Khafizov*, Ramil N. Khafizov, Azat A. Nurmiev, and Ilgiz G. Galiev \\ Kazan State Agrarian University, 420015 Kazan, Russia
}

\begin{abstract}
The article presents the results of a study to identify the optimal value of the annual load on one tractor using direct sowing technology. The optimal annual load on one tractor is directly associated with the power provision to agriculture and, indirectly, with its productivity. The article analyzes the dependence of the annual tractor load in ploughland per ha on various factors of the tractor-operator-instrument-fieldsoil-crop system: on tractor parameters; unit; environment and it is concluded that the optimal annual load on one tractor depends on them. The method of choosing various agricultural enterprises power supply should be connected with the natural and climatic conditions of their production activities, accepted technologies for cultivating crops, soil types, field sizes, etc. It was revealed that in Russia the optimal energy supply of agriculture with the power of tractor engines, using the zero tillage technology, is in the range from 2.4 to $2.8 \mathrm{hp} / \mathrm{ha}$.
\end{abstract}

\section{Introduction}

The annual tractor load per ha determines the equipment use intensity. In recent years, this indicator for the Russian Federation has been constantly increasing, as can be seen from Figure 1 [1, 2].

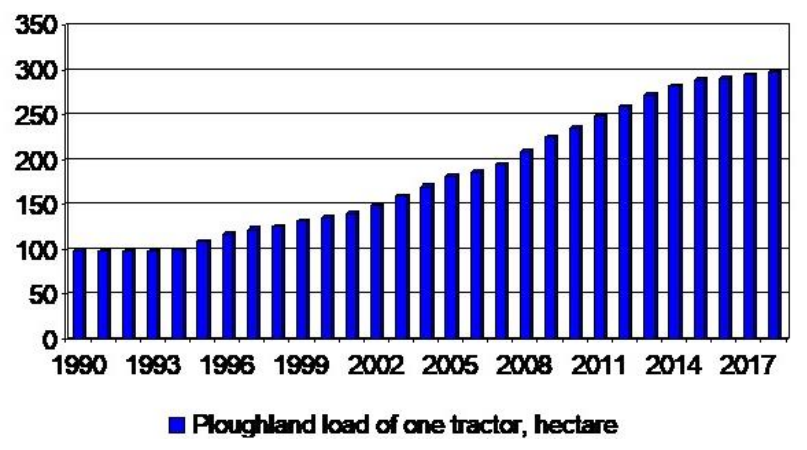

Fig. 1. The ploughland load of one tractor in the Russian Federation by years

However, this approach is not entirely correct, because we do not know if tractors were unify by the same denominator. We do not know, if the load in ha is given to a real tractor or conventional reference.

Literature sources differ. Therefore, it is more correct to characterize the provision level of agricultural production with tractors, the main means of agricultural production mechanization, by energy supply of ploughland per one hectare in hp.

It can be assumed or hypothesized that the greater the power supply per 1 hectare of ploughland, the greater the productivity of agricultural workers and the shorter the time the technological operations are carried out, which means that there will be less loss of potential crop.

Figures 2, 3, 4 demonstrate information on power supply in foreign countries and in the Russian Federation $[3,4]$.

As it can be seen from Figure 2, the highest power supply is recorded in the USA - 8.5 hp / ha and in the European Union (EU) countries $5 \mathrm{hp} / \mathrm{ha}$ and, accordingly, they have the highest yield of grain crops.

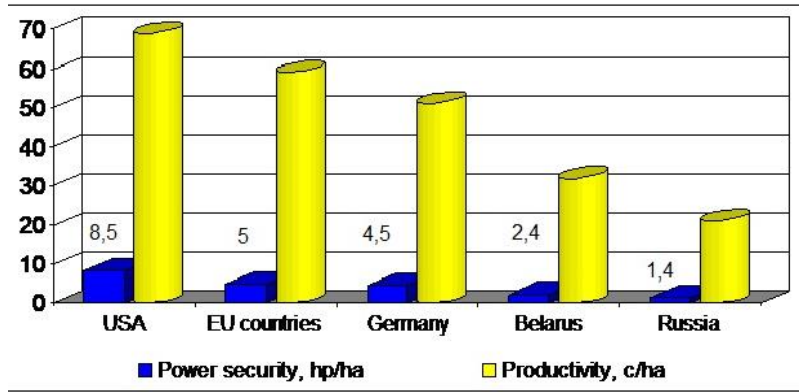

Fig 2. Energy supply in the EU, USA and Russia and its correlation with the grain crops yield (average 5 years)

Figure 3 shows that the power supply of agriculture in India is constantly growing, which lead to a stable increase in productivity. Energy supply in 2011 reached $1.75 \mathrm{~kW} / \mathrm{ha}$, which provide the increase in productivity in India to $17.8 \mathrm{c} / \mathrm{ha}$.

To prove the directly proportional relationship between the energy supply of agriculture (crop production) and the grain crops yield, typical for Russia, Figure 4 shows the power security of its regions [1].

* Corresponding author: fts-kgau@ mail.ru 


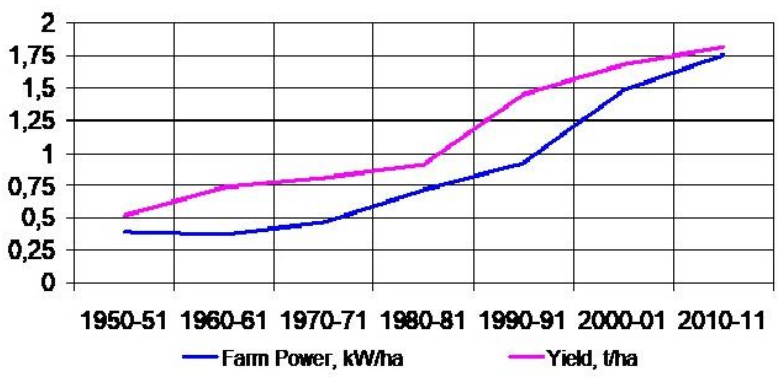

Fig. 3. Power supply of agriculture in India by years and its correlation with the grain crops yield

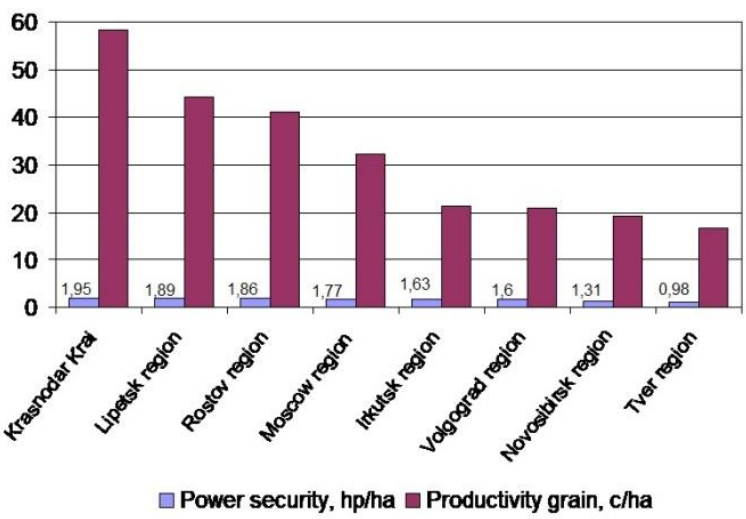

Fig. 4. Energy supply in some regions of Russia and its correlation with the grain crops yield

The most power secure region is Krasnodar Krai $1.95 \mathrm{hp} / \mathrm{ha}$, and there is the highest grain crops yield $58.3 \mathrm{c} / \mathrm{ha}$. In the Tver region, grain yield is $16.7 \mathrm{~kg} / \mathrm{ha}$ with power security of $0.982 \mathrm{hp} / \mathrm{ha}$.

Considering the fact that the power supply in different countries, and within the Russian regions, varies greatly, the question arises: What is the optimal power supply of agriculture, what is the optimal load on one tractor?

This article is answering to this question. The proposed solution is acceptable for the technology of crops cultivation with zero tillage, relates to optimization problems.

\section{Materials and methods}

The optimal annual load on tractors can be determined on the basis of optimizing the composition of the machine-tractor fleet (MTF) on the enterprise, which is a process of calculating the qualitative and quantitative composition of the equipment used, as a result of which agricultural work will be carried out in optimal agrotechnical terms, which will help to obtain high and stable yields with minimal resource costs.

The existing methods used to solve the optimization problems of the MTF are differ [5-16] by:

1. Optimization criterion;

2. Used mathematical apparatus [11-16].

The most widely used optimization criteria are:

- minimum power machines [5-7];

- minimum of direct operating costs [8];
- minimum of reduced costs $[13,14]$;

- minimum fuel consumption [16];

- minimum labor costs [12].

However, all existing mathematical models of MTFs have a drawback - they use either particular optimization criteria or a global, synthesizing, but economic criterion - reduced costs - is a subjective indicator, and, moreover, does not take into account the technical parameters stress on the crop being formed.

The article proposes to use an objective, integrated criterion - total energy costs [17] as a criterion for optimizing the MTFs composition and the parameters of a machine and tractor unit in a technological operation.

$$
\begin{aligned}
E=E_{\mathrm{m}}+E_{\mathrm{m} . \mathrm{sch} .}+E_{\mathrm{m} . \mathrm{oth} .}+\underset{\rightarrow \min }{E_{\mathrm{crm}}+E_{\text {a.d.. }}+E_{\mathrm{ctrl}}+E_{\mathrm{b} . \mathrm{f}}+E_{\text {lost }}} \\
\rightarrow \text { min }
\end{aligned}
$$

where $E$ - specific total energy costs, MJ / ha; $E_{\mathrm{m}}$ energy spent on the manufacture of a tractor, implement, trailer per 1 ha, $\mathrm{MJ} / \mathrm{ha}$; $E_{\mathrm{crm}}$ - energy spent on overhaul, current repair and maintenance of a tractor, trailer and implement, $\mathrm{MJ} /$ ha; $E_{\text {a.d. }}$ - energy spent on assembly and disassembly of the unit, MJ / ha; $E_{\text {ctrl }}$ - energy spent on tractor control (gear shifting, turns, stopping and moving away), MJ / ha; $E_{\mathrm{b} . \mathrm{f}}$ is the energy spent on the unit to perform work by burning fuel, $\mathrm{MJ} / \mathrm{ha}$; $E_{\text {lost- }}$ crop energy lost due to an not optimally selected brand of tractor, parameters and operating modes of the unit, $\mathrm{MJ} / \mathrm{ha}$.

Based on the proposed criterion for optimizing the parameters of the units and determining the composition of the machine-tractor fleet, a mathematical model of various units in technological operations has been developed [18-20]. The model allows for various optimization calculations, including the identification of the optimal annual tractor load for various technological operations, taking into account the stress of environmental factors and tractor parameters on the formed crop yield.

\section{Results}

Using the developed energy mathematical model of machine-tractor units, simulation experiments were conducted to determine the optimal annual load for tractors from various manufacturers, the results of which are shown in Figure 5. The used technology of cultivating crops - no till.

The initial data for the calculation:

The area of the field, ha. $=100$

Headland, km. $=1$

Relocation distance, $\mathrm{km} .=3$

Seed density, $\mathrm{kg} / \mathrm{m} 3=800$

The coefficient of bearing surface strength $=0.9$

Volume of work, ha $=\mathrm{X}$

The number of tractors performing the operation $=1$

The number of working hours per day $=16$

Planned productivity of the main and by-products, $\mathrm{kg}$ / ha. $=40$

Tire pressure of tractor wheels (from 0.08 to 0.2 ), $\mathrm{MPa}=0.16$

The number of wheels on one side of the tractor ( 1 or 2 or 3 , etc.) $=1$ 
Wheel grip coefficient $=0.6$

Tractor wheel rolling resistance coefficient $=0.16$

The minimum total energy costs are provided by caterpillar tractors - see Figure 5.

The optimal design parameters for the John Deere tractor - 9430, corresponding to its minimum total energy consumption: the width of the sowing unit $\mathrm{B}_{\mathrm{opt}}=$ $16.2 \mathrm{~m}$; unit speed $\mathrm{V}_{\text {opt }}=11 \mathrm{~km} / \mathrm{h}$; total energy costs $\mathrm{E}_{\text {min }}$ $=17623 \mathrm{MJ} / \mathrm{ha}$ are obtained at an annual tractor load of 180 ha.

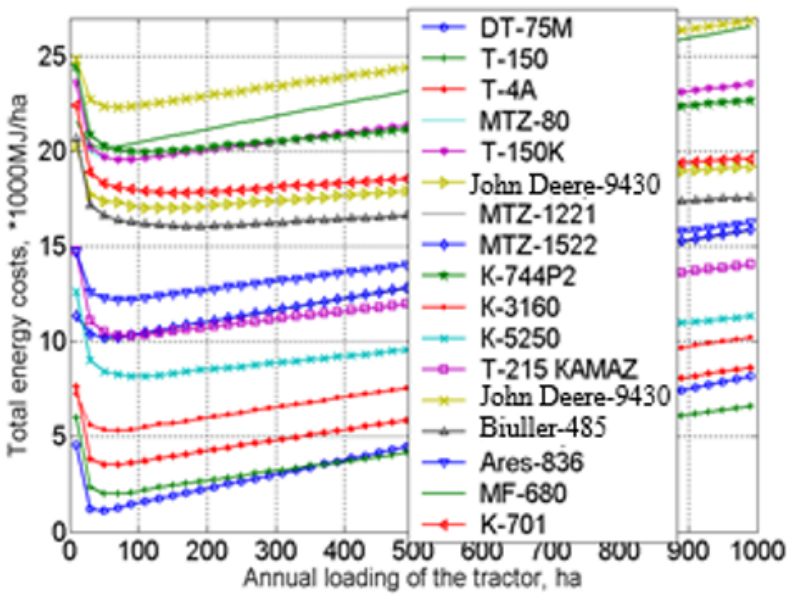

Fig. 5. Dependence of total energy costs (1000 MJ / ha) on the annual load of sowing units with tractors from various manufacturers

For other brands of tractors, see table 1, the optimal value of the annual load varies. This suggests that the optimal load on the tractor depends on the parameters of the tractor - its mass, engine power and other factors.

Table 1. Optimal values of the annual load for individual brands of tractors and energy supply of ploughland with tractor power

\begin{tabular}{|c|c|c|c|c|c|c|c|c|c|c|c|}
\hline \multirow{2}{*}{ 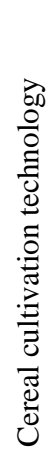 } & \multicolumn{5}{|c|}{$\begin{array}{l}\text { Engine power, hp } \\
\text { / optimal load, ha } \\
\text { by brand of } \\
\text { tractor }\end{array}$} & \multicolumn{5}{|c|}{$\begin{array}{l}\text { Optimal power supply of } \\
1 \text { ha of ploughland by } \\
\text { tractor brands, } \\
\text { hp / ha }\end{array}$} & \multirow{2}{*}{ 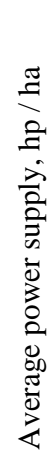 } \\
\hline & $\begin{array}{l}\stackrel{0}{+} \\
\stackrel{+}{a} \\
\hat{1} \\
\hat{\theta}\end{array}$ & 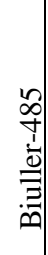 & 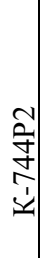 & $\begin{array}{l}n \\
\stackrel{n}{n} \\
\stackrel{n}{n}\end{array}$ & 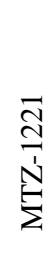 & $\begin{array}{l}\stackrel{0}{+} \\
\dot{+} \\
\hat{1} \\
\hat{\theta}\end{array}$ & 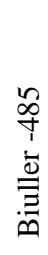 & 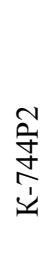 & $\begin{array}{l}\stackrel{n}{\sim} \\
\stackrel{\sim}{H}\end{array}$ & 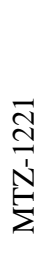 & \\
\hline 유 & 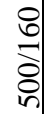 & 匙 & 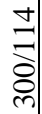 & 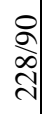 & 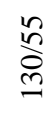 & $\frac{I}{m}$ & $\frac{I}{m}$ & $\begin{array}{l}\hat{\sigma} \\
i\end{array}$ & $\begin{array}{l}n \\
\sim \\
i\end{array}$ & $\stackrel{\text { ñ }}{\text { ñ }}$ & $\frac{2}{i}$ \\
\hline
\end{tabular}

Let us carry out calculations to identify the influence of various environmental factors and tractor parameters on the optimal annual tractor load John Deere - 9430 when performing direct sowing.
Let us consider the effect of the resistivity of an agricultural machine. The calculation data are shown in Figure 6.

The influence of the cultivated field area on the optimal value of the annual load of the sowing unit with a John Deere-9430 tractor is shown in Figure 7.

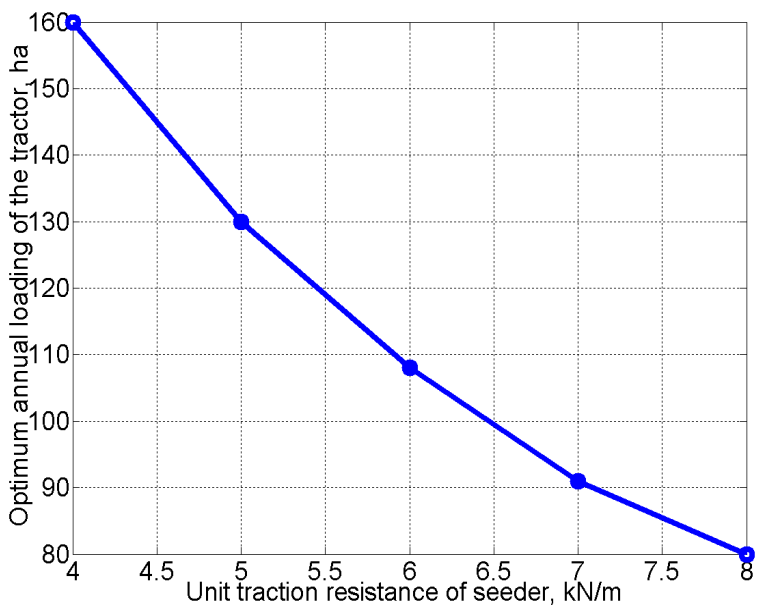

Fig. 6. The resistance stress of the agricultural machine on the optimal value of the sowing unit annual load with a tractor John Deere - 9430

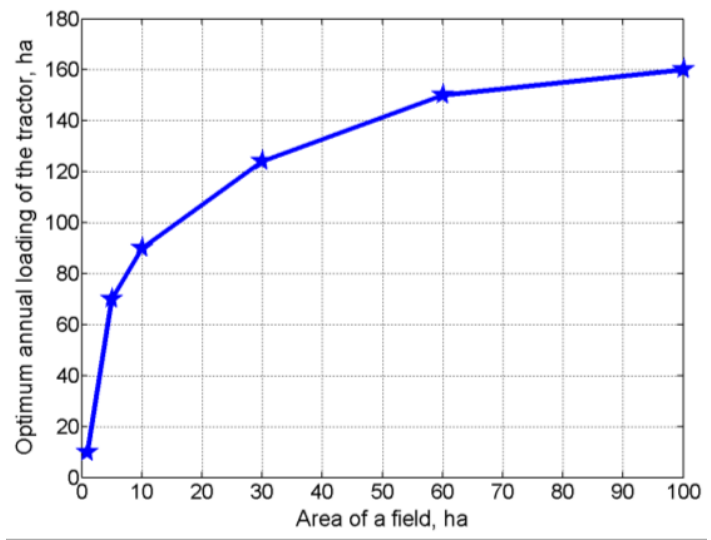

Fig. 7. The cultivated field stress on the optimal value of the sowing unit annual load with a tractor John Deere-9430

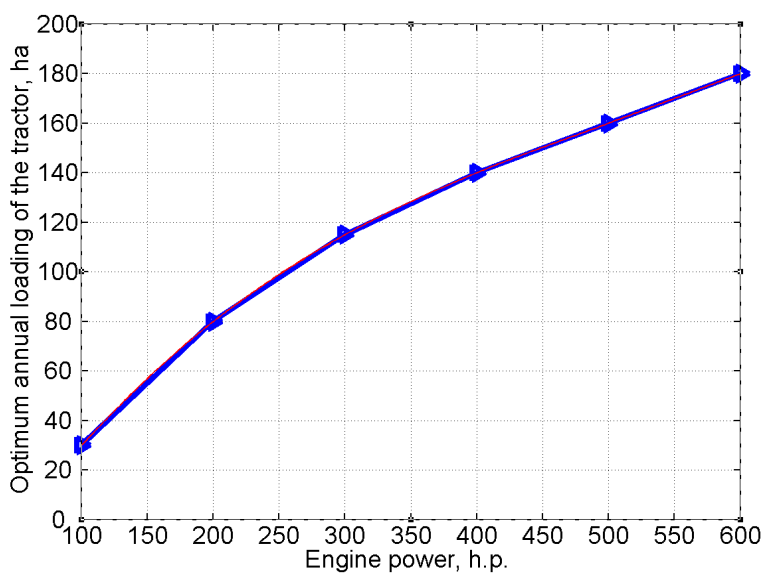

Fig. 8. The engine power influence on the optimal value of the sowing unit annual load with John Deere - 9430 tractor 
Figure 8 demonstrates the influence on the optimal value of the sowing unit annual load with John Deere 9430 tractor power of its engine.

Significant was the influence of the width of the sowing unit on the optimal annual load of the John Deere tractor - 9430, as can be seen from Figure 9.

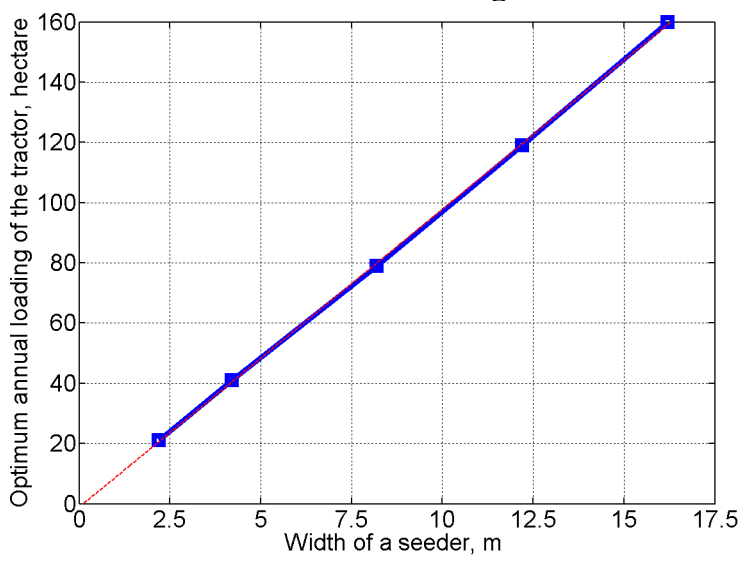

Fig. 9. The influence of the sowing unit's width on the optimal value of the John Deere- 9430 tractor annual load

Figure 10 shows that the greater the speed of the unit, which is limited by engine power, the greater the optimal annual load of the John Deere- 9430 tractor.

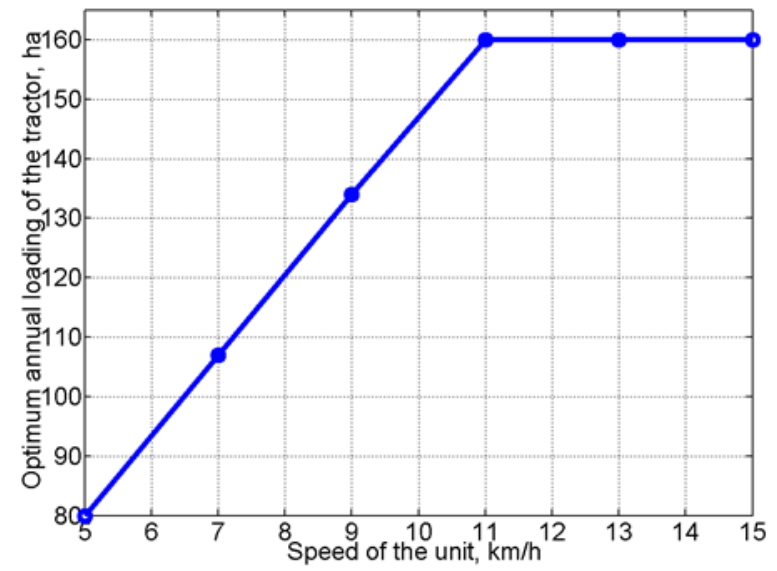

Fig. 10. The sowing unit speed effect on the optimal value of the John Deere - 9430 tractor annual load

\section{Discussion}

When performing a technological operation, in particular on grain crops' direct sowing, there is an optimal value of the annual load on the tractor, which varies by tractor brands. With an optimal annual tractor load, the total energy costs in MJ / ha will be minimal. With a decrease in the annual load and with its increase from the optimal value, the total energy costs increase. The higher the tractor traction class, the greater the optimal annual load on the tractor, as it can be seen from Figure 5. The increase in total energy costs when exceeding the optimal annual load on the tractor in ha is explained by an increase in the term of the technological operation, which means an increase in the yield energy, which is lost due to the increase in the term of the technological operation.
The increase in total energy costs while lowering the annual load below the optimal value is explained by the increase in the components of the total energy costs spent on depreciation of equipment, its maintenance and repair.

During computational experiments, it was found that the optimal annual load on the tractor depends on a number of environmental factors and the parameters of the tractor and the unit.

It has been established that there is a non-linear relationship between the specific traction resistance of an agricultural machine and the optimal annual tractor load - Figure 6. Moreover, the greater the traction resistance of an agricultural machine, the less the annual tractor load should be. From the energy mathematical model of the aggregates, it is clear that the greater the traction resistance of an agricultural machine operating as part of the aggregate, the lower the productivity of the aggregate in one hour of the shift time, which means that the time to complete the technological operation increases and crop losses increase due to violation of the agrotechnical timing of the technological operations. Therefore, the decrease in the optimal annual load on the tractor, with an increase in the specific traction resistance of the agricultural machine, expressed in $\mathrm{kN} / \mathrm{m}$.

Figure 7 shows the data of computational experiments. The influence on the value of the optimal annual load on the tractor of such an environmental factor as the size of the treated field is shown. It can be seen from the figure that the larger the size of the field being cultivated, the greater the value of the optimal annual load per tractor. This suggests that if, according to the climatic conditions of the region, the average fields are small (this is typical for the Caucasus regions within the Russian Federation), then the optimal annual tractor load should be less and the region's power supply should be higher than in regions with large areas processed fields.

This phenomenon is explained by on the mathematical model of aggregates - the larger the area of the field being cultivated, the greater the productivity of the aggregate and, consequently, less yield loss due to violation of the agro-technical timelines for the technological operation.

From Figure 5, and especially from Figure 8, it is clearly seen that the larger the tractor's traction class, which means its mass and the greater the tractor engine power, the greater the optimal annual tractor load.

Figure 8 shows that there is a saturation limit of the tractor with a certain mass, accompanying its power.

For the John Deere-9430 tractor, the maximum power value is in the range of $600 \mathrm{hp}$, after exceeding which the optimal annual tractor load ceases to grow rapidly. A further increase in power and the optimal value of the annual load on the tractor should be accompanied by an increase in the mass of the tractor to realize the increased power through the traction and coupling qualities of the tractor.

The increase in the optimal value of the annual tractor load due to an increase in the tractor engine power is explained by an increase in the unit's 
productivity due to an increase in the unit's operating speed. An increase in the productivity of a single unit leads to a decrease in potential crop losses due to violation of the agro-technical timelines for the technological operation.

As can be seen from Figure 9, the influence on the annual tractor load's optimal value on the direct sowing of the implement width is linear. Moreover, the wider the grip width of a sowing unit with a John Deere-9430 tractor, the greater the optimal annual load on the tractor, which indicates the need to use wide-grip units, both in sowing and in other technological operations in the production processes of grain cultivation, as in RF, and beyond.

The increase in the optimal value of the annual load on one tractor when performing direct sowing with an increase in the working width of the aggregates is explained by a decrease in grain energy lost, both due to a decrease in the agro-term of the technological operation and due to the lesser compaction effect of tractor movers on the soil. In the latter case, with an increase in the working width of the aggregate, the compacted area of the cultivated field decreases, which means that the yield energy lost due to increase in the denser soil on the field.

The technological operation's speed depends on the agro-technically permissible limits of the unit's working speed when agro-technical requirements for the quality of the technological operation are observed. To increase the speed of the technological operation, within the unit's permissible speed, it is necessary to increase the tractor engine power. At the same time, the productivity of the unit increases, which means that the execution time of the technological operation decreases, which, of course, is accompanied by a decrease in the energy of the lost crop.

With the selected width of the unit, it is advantageous to work at a higher unit speed. At the same time, total energy costs are reduced, and the optimal annual load on the tractor grows, as it can be seen from Figure 10 .

\section{Conclusion}

1. Productivity in the agricultural sector of the economy and, ultimately, crop yields depend on the annual tractor load or the power supply of agricultural production. The higher the power supply of production, the greater the grain crops yield, as evidenced by the practice of developed and developing countries.

2. The optimal power supply of agricultural production depends on the parameters of the main mechanization means of production - the mass of the tractor, the power of its engine, as well as environmental factors of the system: tractor-operator-instrument-fieldsoil-crop.

3. The optimal annual tractor load is greater, when the tractor engine power, the width of the machine, its speed, the area of one field on which the machine works are greater. The optimal annual tractor load also depends on the energy intensity of the technological operation, and it is smaller, when the specific traction resistance of an agricultural machine is greater.

4. The analysis of the influence of various factors on the optimal annual tractor load shows that for the climatic conditions of the Republic of Tatarstan, when applying the technology of cultivating crops without tillage (no till), the optimal energy supply of agricultural production is in the range from 2.4 to $2.8 \mathrm{hp} / \mathrm{ha}$. With the transition of farmers to technologies of minimal tillage and intensive technologies, the value of the necessary optimal energy supply of production will increase due to the need for several technological operations simultaneously. Unfortunately, the energy supply of agricultural production in the Republic of Tatarstan today is in the region of $1.40 \mathrm{hp} / \mathrm{ha}$, which indicates the lack of energy supply of the republic in the field of agricultural production and the potential for labor productivity increase.

\section{References}

1. Regions of Russia. Socio-economic indicators. 2018: Stat. Sat (Rosstat, Moscow, 2018)

2. Federal State Statistics Service: Official site. Federal State Statistics Service (1995-2015) Retrieved from: http://www.gks.ru

3. A. Ezhevskii, What are our goals? Agricultural Review 6, 16-19 (2013)

4. A. Didar Singh, R. Kapur, Transforming agriculture through mechanisation. A Knowledge Paper on Indian farm equipment sector. Agriculture Division (Federation House, Tansen Marg. New Delhi, 2015)

5. S.K. Mironiuk, The use of transport in agriculture (Kolos, Moscow, 1982)

6. S.A. Iofinov, G.P. Lyshko, Operation of the machine and tractor fleet (Kolos, Moscow, 1984)

7. L.A. Zangiev, G.P. Lyshko, Production operation of the machine-tractor fleet (Kolos, Moscow, 1996)

8. A.P. Kasianov, Planning in agricultural enterprises (Kolos, Moscow, 1982)

9. V.Z. Bubnov, M.V. Kuzmin, Operation of the machine and tractor fleet (Kolos, Moscow, 1980)

10. L.I. Kushnarev, Improving the technical service of the MPF machine and tractor fleet (Moscow State Agroengineering university named after V.P. Goriachkin, Moscow, 2002)

11. V.M. Lapteva, Modeling the composition of the machine and tractor fleet (Kolos, Moscow, 1999)

12. I.V. Orlova, V.A. Polovnikov, Economicmathematical methods and models: computer modeling (2014)

13. L.E. Khazanova, Mathematical modeling in economics (BeK Publishing House, 1998)

14. V.A. Goberman, Automobile transport in agricultural production (Transport, Moscow, 1986)

15. G.P. Seliukov, Educational-methodical complex: Mathematical modeling of production and economic processes (Tyumen, 2010) 
16. E.V. Berezhnaia, V.I. Berezhnoi, Mathematical methods for modeling economic systems (Finance and Statistics, Moscow, 2001)

17. C.A. Khafizov, Ways to reduce energy costs in production processes in agriculture (Kazan University, 2007)

18. C. Khafizov, R. Khafizov, A. Nurmiev, B. Ziganshin, Optimization of main parameters of tractor working with soil-processing implement in Contents of Proc. of $17^{\text {th }}$ Int. Scientific Conf. Engineering for rural development 168-175 (Jelgava, 2018)
19. C. Khafizov, R. Khafizov, A. Nurmiev, I. Galiev, Optimization of main parameters of tractor and unit for seeding cereal crops with regards to their impact on crop productivity in Contents of Proc. of $17^{\text {th }}$ Int. Scientific Conf. Engineering for rural development 176-185 (Jelgava, 2018)

20. C. Khafizov, A. Nurmiev, R. Khafizov, N Adigamov, Method of justification for parameters of tractor-implement unit with regards to their impact on crop productivity in Contents of Proc. of $17^{\text {th }}$ Int. Scientific Conf. Engineering for rural development 161-167 (Jelgava, 2018) 